Appl. Ent. Zool. 26 (4) : 449-456 (1991)

\title{
Survival Rates for Two Dung Beetle Species, Onthophagus lenzii HAROLD and Liatongus phanaeoides WESTWOOD (Coleoptera: Scarabaeidae), in the Field
}

\author{
Hironori YASUDA ${ }^{1}$ \\ Laboratory of Applied Entomology and Nematology, \\ Faculty of Agriculture, Nagoya University, \\ Nagoya 464, Japan
}

(Received December 10, 1990; Accepted May 2, 1991)

\begin{abstract}
Survival rates from egg to adult, including the survival rates during winter, were studied in the field for two dung beetle species, Onthophagus lenzii and Liatongus phanaeoides, from 1984 to 1987. To examine the effect of insects coming into dung pats on the survival rates of the two species, the survival rates were assessed under two sets of rearing conditions, one with a dung pat and the other without a dung pat on the soil surface. The survival rates from egg to adult before overwintering were $50.0 \%$ (without dung) in $1985,52.4 \%$ (without dung), $55.0 \%$ (with dung) in 1986 for O. lenzii. For L. phanaeoides the survival rates, including the overwintering larval survival rates, were $32.0 \%$ (without dung), $33.6 \%$ (with dung) in 1985 , $50.0 \%$ (without dung) in 1986. For both species the survival rates from egg to adult in the plot with dung were not lower than those without dung. This suggested that the effect of the insects coming into dung pats on the survival rates was negligible. Onthophagus lenzii overwinters as an adult, and the overwintering survival rates were $68.0 \%$ in $1984 / 85,25.0 \%$ in $1985 / 86$, and $51.0 \%$ in $1986 / 87$ for five pairs, and $63.8 \%$ in $1984 / 85,12.0 \%$ in $1985 / 86$, and $47.0 \%$ in $1986 / 87$ for ten pairs. Liatongus phanaeoides overwinters as a larva. The survival rates were $52.9 \%$ in $1985 / 86$ and $83.3 \%$ in $1986 / 87$. The overwintering survival rates for both species were lower in 1985/86 when winter temperature was low. The survival rates from egg to pre-reproductive adult, including the survival rates during winter, were $9.0 \%$ in 1985 and $26.0 \%$ in 1986 for $O$. lenzii; $33.0 \%$ in 1985 and $50.0 \%$ in 1986 for $L$. phanaeoides. The higher population density of $O$. lenzii, compared with that of $L$. phanaeoides, may not be attributable to their survival rates.

Key words: survival rate, dung beetle
\end{abstract}

\section{INTRODUCTION}

Coprophagous beetles use dung as food as well as oviposition sites. Some large species construct burrows in the soil, insert a dung ball into each burrow, and lay a single egg in it. This reproductive behaviour is beneficial to the recycling of pasture nutrients and the reduction of pest flies (e.g. WATERhouse, 1974). Most of the studies concerning dung beetles have dealt with reproductive behaviour (e.g. Klemperer, 1983; Sato and Imamori, 1987), pest fly control (e.g. Macqueen and Beirne, 1975),

\footnotetext{
1 Present address: Insect Toxicology, and Physiology, The Institute of Physical and Chemical Research, Hirosawa 2-1, Wako, Saitama 351-01, Japan
} 
seasonal occurrence (e.g. White, 1960; YASUdA, 1984), movement pattern (e.g. Hanski, 1980a; Yasuda, 1987), and community structure (e.g. Hanski, 1980b; Holter, 1982), but few studies have been carried out in the field regarding the survival rate from egg to adult.

Onthophagus lenzii and Liatongus phanaeoides coexist in cattle dung in the pasture of central Japan (Yasuda, 1984). These two species have similar oviposition modes, and their oviposition periods overlap each other. Onthophagus lenzii overwinters in adult stage in the soil. Overwintered adults appear from late May to late August and construct oval-shaped dung balls under a dung pat, laying a single egg in each of them. The developmental period of the larva is about one month, and new adults are seen on the ground in late August to late October. Liatongus phanaeoides overwinters as a third instar, which becomes an adult in mid June. The new adult appears from mid June to September. This species also constructs dung balls and lays a single egg in each of them.

The potential life time fecundity of $O$. lenzii was less than that of $L$. phanaeoides (Yasuda, 1986). Nevertheless, the population density of the adults of O. lenzii was higher than that of $L$. phanaeoides (YASUDA, 1987). Therefore, the survival rate from egg to adult might be important as a determinant of population density of each species.

This paper describes the overwintering survival rates and the egg-to-adult survival rates of the two species based on two kinds of experiments, one with and the other without a dung pat, assessing the effect of insects coming into a dung pat on the survival rates, and suggests the influence of the survival rates on the difference of population densities of the two species.

\section{MATERIALS AND METHODS}

Survival rate from egg to adult. The studies were carried out at the High Land Agricultural Experimental Station of Nagoya University in central Japan (altitude about $650 \mathrm{~m}$ ). Two pairs of adults of both species were reared in individual experimental containers to obtain dung balls for the survival rate experiment in 1985 and 1986 (see YASUDA, 1989; Fig. 1). The dung balls were taken out of the container after three days, and five or ten balls were put into each of the experimental containers with soil. The containers were placed into the ground at the pasture until the adult emergence. After the adult emergence, the balls were withdrawn from the container to investigate mortality. Experimental periods and replications are shown in Table 1. Since the container used for this experiment was a plastic basket with a $2 \mathrm{~mm}$ mesh (26 $\mathrm{cm}$ in diameter, $12 \mathrm{~cm}$ in depth), large organisms living in the soil would be prevented from reaching the balls. To study the effect of insect intrusion into the dung pats on the survival rates, the survival rates were assessed under two sets of rearing conditions, one with and the other without a dung pat $(1 \mathrm{~kg})$ on the soil surface of the containers. The experiment was carried out in 1986 for O. lenzii and in 1985 for $L$. phanaeoides (Table 1 (a), (b)). The stages of individuals that had died in the dung balls were determined as follows: (1) egg mortality, when a ball did not contain a dead larva, pupa, or an adult; (2) larval or pupal mortality, when a ball included a dead larva or pupa; and (3) adult emergence, when a ball had a pupating room containing soil caused by adult emergence.

Determination of stadium. I reared two pairs of adults of each species in the experi- 
Table 1. Experimental periods and replications of the survival rate experiments for two species, Onthophagus lenzii and Liatongus phanaeoides

\begin{tabular}{|c|c|c|c|c|c|}
\hline Species & Year & & Period & Replication & $\begin{array}{c}\text { No. of } \\
\text { dung balls }\end{array}$ \\
\hline \multirow[t]{3}{*}{ O. lenzii } & 1985 & (a) & 1 August-30 October & 8 & 40 \\
\hline & 1986 & (a) & 15 July -15 October & 7 & 70 \\
\hline & & (b) & 15 July -15 October & 8 & 80 \\
\hline \multirow[t]{3}{*}{ L. phanaeoides } & 1985 & (a) & 1 September-1 July & 10 & 100 \\
\hline & & (b) & 1 September-1 July & 11 & 110 \\
\hline & 1986 & (a) & 10 September-1 June & 5 & 50 \\
\hline
\end{tabular}

(a): plot with a dung pat, (b): plot without a dung pat.

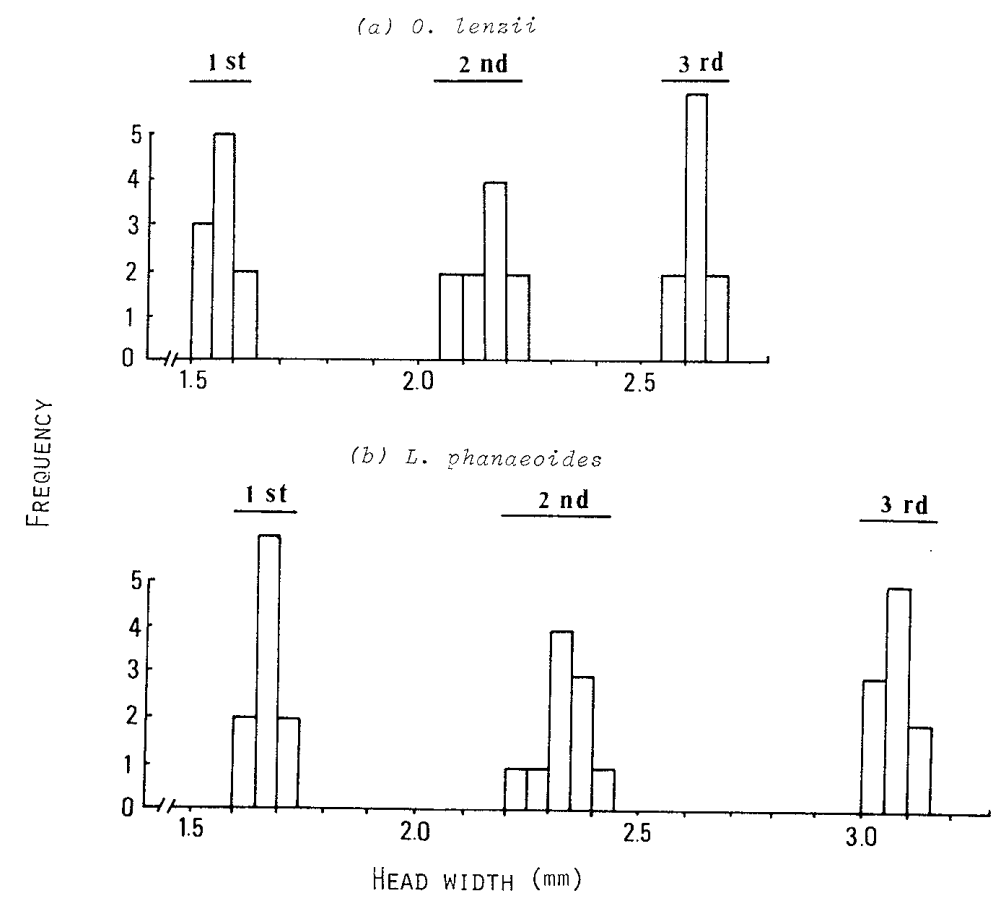

Fig. 1. Distribution of width of larval head-capsules.

mental containers (see YASUdA, 1989; Fig. 1) and picked out five dung balls from the containers every fifth day. I measured the width of the head capsule of the larva with a microscope. The measurements were performed during the period of August 1 to 30, 1985 for O. lenzii and August 20 to September 20, 1984 for L. phanaeoides.

Using the results obtained by these measurements, I determined the stadium of a dead larva in a dung ball from the width $(W)$ of the head capsule as follows (Fig. 1): for O. lenzii (1) $W<1.70 \mathrm{~mm}$ as the first instar, (2) $2.00 \mathrm{~mm}<W<2.30 \mathrm{~mm}$ as the second instar, (3) $W>2.50 \mathrm{~mm}$ as the third instar; for $L$. phanaeoides (1) $W<1.80 \mathrm{~mm}$ as the first instar, (2) $2.10 \mathrm{~mm}<W<2.50 \mathrm{~mm}$ as the second instar, (3) $W>3.00 \mathrm{~mm}$ as the third instar.

Overwintering survival rate. New adults of $O$. lenzii were caught in the field and released into the experimental container with a dung pat $(1 \mathrm{~kg})$, similar to the container 
for the survival rate experiment, and then the container was covered with a plastic basket. These containers were placed in the field until the following spring, and the number of live individuals in the containers was counted. The experiments were carried out for three successive winters (October 27, 1984-May 8, 1985; October 30, 1985-May 26, 1986; October 27, 1986-April 29, 1987). Numbers of pairs released into each container were 5, 10, 20, and 30 pairs for 1984/85 and 1985/86, and five and ten pairs for $1986 / 87$.

On the other hand, L. phanaeoides overwinters as a third instar. The number of individuals overwintered was estimated from the data obtained by the survival rate experiment mentioned earlier. Since the third instar makes a room in a dung ball before overwintering, I examined the dung balls for the presence of this room to determine whether the third instar had died before or during the overwintering.

\section{RESULTS}

In $O$. lenzii, the survival rates from egg to adult before overwintering were high (Fig. 2). The mortality at the egg stage was higher than that at other stages in each year. There was no indication that the mortality in the plot with dung was higher than that in the plot without the dung ( $G$-test, $p>0.05)$.

The survival rates of adult $O$. lenzii during overwintering are shown in Table 2. The survival rates at five pairs were significantly higher than those at 30 pairs in $1984 / 85$ and $1985 / 86(p<0.05)$. However, the differences in the survival rates were not significant between other densities $(p>0.05)$ except in 1985/86. There was no significant difference between males and females in the survival rate $(p<0.05)$ except at 30 pairs in 1984/85 ( $G$-test, $p<0.05)$. The survival rates were high in 1984/85 and 1986/ 87 , but low in $1985 / 86$. Figure 3 shows the relationship between survival rates (mean

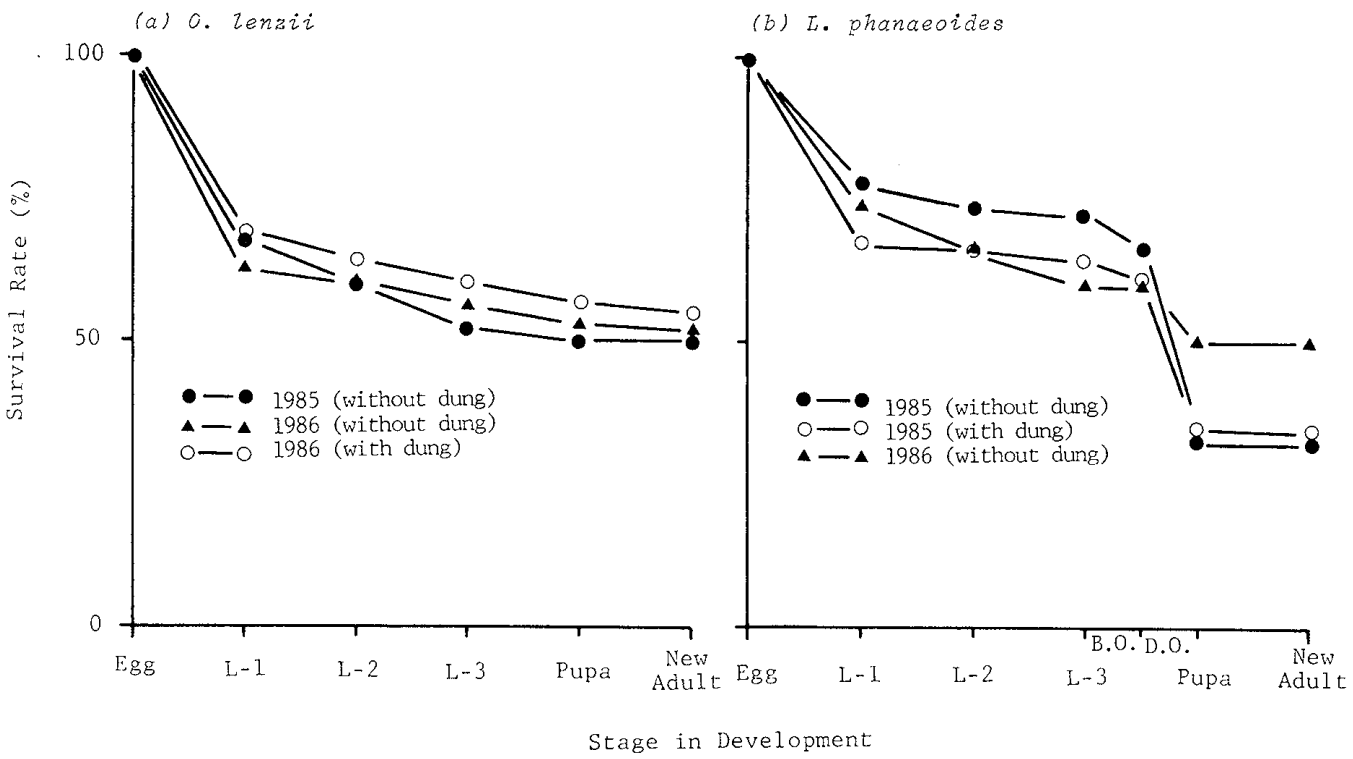

Fig. 2. Survivorship curves of $O$. lenzii (a) and L. phanaeoides (b). (B.O.: before overwintering, D.O.: during overwintering) 
Table 2. Overwintering of adult Onthophagus lenzii

\begin{tabular}{|c|c|c|c|c|c|}
\hline & \multirow{2}{*}{$\begin{array}{l}\text { No. of pairs } \\
\text { added }\end{array}$} & \multirow{2}{*}{$\mathrm{n}$} & \multicolumn{2}{|c|}{ No. of Survivorsa } & \multirow{2}{*}{$\begin{array}{l}\text { Survival } \\
\text { rate }^{b}\end{array}$} \\
\hline & & & $\hat{\delta}$ & 우 & \\
\hline \multirow[t]{4}{*}{$1984 / 85$} & 5 & 5 & $3.4 \pm 1.6$ & $3.4 \pm 1.1$ & $68.0 \mathrm{a}$ \\
\hline & 10 & 4 & $5.5 \pm 0.6$ & $7.3 \pm 1.3$ & $63.8 \mathrm{ab}$ \\
\hline & 20 & 4 & $13.0 \pm 2.0$ & $11.7 \pm 3.1$ & $61.7 \mathrm{ab}$ \\
\hline & 30 & 2 & $12.0 \pm 0.0$ & $20.5 \pm 0.7$ & $54.2 \mathrm{~b}$ \\
\hline \multirow[t]{4}{*}{$1985 / 86$} & 5 & 7 & $1.0 \pm 0.6$ & $1.0 \pm 0.7$ & $25.0 \mathrm{a}$ \\
\hline & 10 & 7 & $1.0 \pm 0.6$ & $1.2 \pm 0.7$ & $12.0 \mathrm{bc}$ \\
\hline & 20 & 7 & $3.3 \pm 1.3$ & $2.6 \pm 1.4$ & $17.1 \mathrm{ac}$ \\
\hline & 30 & 3 & $3.0 \pm 1.0$ & $3.6 \pm 1.0$ & $7.1 \mathrm{~b}$ \\
\hline \multirow[t]{2}{*}{$1986 / 87$} & 5 & 6 & $2.5 \pm 0.5$ & $2.6 \pm 0.5$ & $51.0 \mathrm{a}$ \\
\hline & 10 & 7 & $4.7 \pm 0.8$ & $4.9 \pm 1.3$ & $47.0 \mathrm{a}$ \\
\hline
\end{tabular}

a Mean \pm S.D.

b Values followed by the same letters are not significantly different by $G$-test $(p>0.05)$.

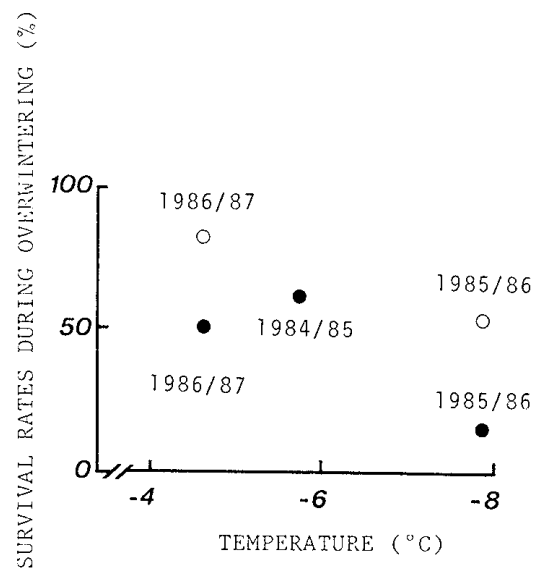

Fig. 3. Relationship between mean temperatures from December to February and survival rates during overwintering of $O$. lenzii $(\bullet)$ and $L$. phanaeoides $(O)$.

values of survival rates in five and ten pairs) during overwintering and mean temperatures from December to February. The rate was low in 1985/86 when the temperature during winter was low. In 1985/86, 63\% (five pairs), 54\% (ten pairs), 55\% (20 pairs), 53\% (30 pairs) of individuals died at the bottom of the experimental container. In other years, however, this phenomenon was not observed.

In L. phanaeoides, the survival rate from egg to adult was also high (Fig. 2). The mortality in the plot with the dung was not higher than that in the plot without the dung ( $G$-test, $p>0.05)$. The overwintering survival rates were $52.9 \%$ in $1985 / 86$ and $83.3 \%$ in $1986 / 87$. The survival rate was also low in the winter with low temperatures (1985/86) (Fig. 3).

The survival rate from egg to pre-reproductive adult, including the survival rate during the winter, was calculated by multiplying age-interval survival rates. For $O$. lenzii the mean value of the survival rates in five and ten pairs shown in Table 2 was used as the overwintering survival rate of adults. In the years when two kinds of the 
survival rate experiments were carried out, the mean value was used for calculation. The estimated values were $9.0 \%$ in 1985 and $26.0 \%$ in 1986 for $O$. lenzii, and $33.0 \%$ in 1985 and $50.0 \%$ in 1986 for L. phanaeoides. The values of $O$. lenzii were lower than those of $L$. phanaeoides ( $G$-test, $p<0.001$ ).

\section{DISCUSSION}

No biological mortality factors for Onthophagus lenzii and Liatongus phanaeoides were revealed in this study, however, the data shown here suggested that insects coming into dung pats, that is, the insects belonging to Scatophagidae, Hydrophilidae, Histeridae, Staphylinidae, and Scarabaeidae, did not play a major role as mortality factors for the two species. Dung-living nematodes destroyed the brood ball of Copris diversus, resulting in beetle larvae dying (Tyndale-Brscoe, 1984), and sometimes earthworms might destroy the eggs of some dung beetles, Bubas bison (KIRK, 1983). AokI (1973) reported that some species of Collembola ate the dung, the pupae of Lepidoptera, nematodes, and other organisms living in the soil. In this study, I found nematodes as well as some species of Collembola in some dung balls in which the eggs had not hatched. Some eggs with nematodes were also observed in other experiments (YAsudA, unpublished). Thus, the effect of organisms living in the soil on the mortality of dung beetles should be made clear in future studies.

The survival rates of $O$. lenzii during winter were $80 \%$ for males and $69 \%$ for females in south western Japan (Hosogr et al., 1979), and 62\% in Korea (PAIK, 1977). At the former site, the adults of $O$. lenzii overwintered in the soil at a depth of $15 \mathrm{~cm}$, which was the bottom of the cage, at the latter, they stayed in the soil at a depth of 20 $\mathrm{cm}$ to $30 \mathrm{~cm}$. The survival rate of adults of $O$. lenzii shown in this study was rather low compared with these results, especially in 1985/86. The depth of the container $(12 \mathrm{~cm})$ used in this experiment may be responsible for the low survival rate. The overwintering survival rates of both species were low when winter temperature was low. The low temperature during winter might cause the survival rate to decrease.

The overwintering survival rates decreased with an increase in the number of adults per pat before winter in some years. The food shortage caused by the harsh intraspecific competition for food before the winter may cause the survival rate to decrease. In this experiment, however, beetles could not escape from the experimental container because the container was covered with a plastic basket. Since the beetles can emigrate easily from the pats with high density and immigrate many fresh pats under natural conditions, the food shortage for this beetles before winter may not be common.

Both $O$. lenzii and L. phanaeoides showed low mortality in their developmental periods except for the egg stage. The collapse as well as disappearance of larval dead body might be attributable to high egg mortality. The survival rates from egg to adult of Aphodius haroldianus and $O$. fodiens, which made dung mass and dung balls, were $77.8 \%$ and $73.7 \%$, respectively, at $20^{\circ} \mathrm{C}$ under laboratory conditions (Hosogr et al., 1980 ), and those for $C$. diversus, which made brood balls, were $76 \%$ with parents and $32 \%$ without parents under field conditions (Tyndale-Biscoe, 1984). Thus, in the dung beetles, the survival rate from egg to adult is rather high compared with other insects (e.g. PrICE, 1984; Itô, 1980). These dung beetles make food provision for each larva. The larva inhabits a dung ball in the soil where the environment might 
be stable. These conditions may result in the high survival rates in dung beetles.

As already mentioned, the potential life time fecundity of $O$. lenzii was less than that of $L$. phanaeoides (YASUDA, 1986). On the other hand, this study showed that the estimated value of survival rate from egg to pre-reproductive adult in O. lenzii was lower than that in L. phanaeoides. Therefore, the population density of $O$. lenzii being higher than that of $L$. phanaeoides may not be attributable to the survival rate from egg to pre-reproductive adult. The data showing the reason for this will be published
elsewhere.

\section{ACKNOWLEDGEMENTS}

I am deeply indebted to Drs. Y. ITô and T. SAITo for their invaluable advice and encouragement during this study. I am grateful to Drs. Y. Sakuratani, E. Hayamizu, and anonymous reviewers for valuable comments. I also thank Dr. A. FonAGy for improving the English of this paper. Thanks are Experimental Station, Dr. H. Yокота, Mr. Y. Itô, and other members of the High Land Agricultural Experimental Station of Nagoya University for help with the field work.

\section{REFERENCES}

Aoki, J. (1973) Soil Zoology: an introduction to classification and ecology of soil animals. Hokuryu-kan, Tokyo,

Hanski, I. (1980 a) Migration to and from cow droppings by coprophagous bectles. Ann. Zool. Fenn. 17:
11-16.

Hanski, I. (1980 b) The community of coprophagous beetles (Coleoptera, Scarabeidae and Hydrophilidae) in northern Europe. Ann. Entomol. Fenn. 46: 57-73.

Holter, P. (1982) Resource utilization and local coexistence in a guild of scarabaeid dung beetles (Aphodius spp.). Oikos 39: 213-227.

Hosogi, Y., H. Hayakawa, K. Shimonishi and M. Miyao (1979) Studies on the utilization of dung beetles for the management of pasture and pasturage sanitation. 7. Seasonal changes of the burial and decomposition of cow dungs by Onthophagus lenzii Har. Bull. Kochi Pref. Exp. Stn. 10: 37-46.

Hosogi, Y., H. Hayakawa, K. Shimonishi and M. Miyao (1980) Studies on the utilization of dung beetles for the management of pasture and pasturage sanitation. 12. Relationships between ambient temperature and growth of dung beetles. Bull. Kochi Pref. Exp. Stn. 11: 45-51.

ITô, Y. (1980) Comparative Ecology. Cambridge University Press, Cambridge, $436 \mathrm{p}$.

KIRk, A. A. (1983) The biology of Bubas bison (L.) (Coleoptera: Scarabaeidae) in southern France and its potential for recycling dung in Australia. Bull. Entomol. Res. 73: 129-136.

Klemperer, H. G. (1983) The evolution of parental behaviour in Scarabaeinae (Coleoptera, Scarabaeidae): an experimental approach. Ecol. Entomol. 8: 49-59.

Macqueen, A. and B. P. Beirne (1975) Dung burial activity and fly control potential of Onthophagus nuchicornis (Coleoptera: Scarabaeinae) in British Columbia. Can. Entomol. 107: 1215-1220.

Park, W. H. (1977) Biology of dung beetles in Korea. In Collected Papers of Dr. PAIK (K. R. Song et al., eds.). Sang Rock Sa, Seoul, pp. 470-511.

Price, P. W. (1984) Insect Ecology. John Wiley and Sons, New York, 607 p.

SAto, H. and M. Imamori (1987) Nesting behaviour of subsocial African ball-roller Kheper platynotus (Coleoptera, Scarabaeidae). Ecol. Entomol. 12: 415-425.

Tyndale-Biscoe, M. (1984) Adaptive significance of brood care of Copris diversus Waterhouse (Coleoptera: Scarabaeidae). Bull. Entomol. Res. 74: 453-461.

YASUDA, H. (1984) Seasonal changes in the number and species of scarabaeid dung beetles in the middle part of Japan. Jpn. J. Appl. Ent. Zool. 28: 217-222.

YASUdA, H. (1986) Fecundity of two dung beetle species, Onthophagus lenzii Harold and Liatongus phanaeoides Westwood (Coleoptera: Scarabaeidae). Appl. Ent. Zool. 21: 177-179. 
YASUDA, H. (1987) Differences in temporal utilization patterns of dung pats among three scarabaeid dung beetles. Res. Popul. Ecol. 29: 167-177.

YAsUdA, H. (1989) Effect of dung conditioning by Onthophagus lenzii Harold on oviposition of Liatongus phanaeoides Westwood (Coleoptera: Scarabaeidae). Appl. Ent. Zool. 24: 488-490.

Waterhouse, D. F. (1974) The biological control of dung. Scient. Am. 230: 100-109.

White, E. (1960) The natural history of some species of Aphodius (Col., Scarabaeidae) in the northern Pennines. Entomol. Mon. Mag. 96: 25-30. 